\title{
Foreign Bodies in Upper Gastrointestinal Tract: A Retrospective Analysis of Clinical Intervention and Management
}

\author{
Loknath Sahoo ${ }^{1 *}$, Rajesh Kumar Padhy ${ }^{2}$, Devanand Mohapatra ${ }^{3}$, Sudeepta Ashe ${ }^{1}$ \\ 1PG Student, 2Professor, Department of ENT, \\ 3Professor, Department of Gastroenterology, \\ Hi-Tech Medical College \& Hospital, Bhubaneswar, Odisha, India.
}

\begin{abstract}
Background: Ingestion of foreign bodies in to the gastrointestinal tract are not uncommon and incidence of airway intrusion and oesophageal obstruction by foreign body may increase the risk factor for morbidity and mortality.

Material and Methodology: A retrospective study was done for 60 patients, admitted in the department of ENT of Hi-Tech medical college \& Hospital, Bhubaneswar during 2014-15.

Result and Observation: Children of 2-10 years age groups were reportedly more victimized $(61 \%)$. The major incidences were attributed to coin ingestion (56\%) followed by fish spine $(25 \%)$, meat bone $(11 \%)$ and safety pin $(5 \%)$, other tablet cover. FB impaction was as high as $75 \%$ at cricopharnyx and $11 \%$ at oropharynx. The patients were managed without any surgical invasion. FBs were retrieved by Magill's forceps with laryngoscopy and flexible oesophagoscopy intervention. No morbidity and mortality was occurred.
\end{abstract}

\section{INTRODUCTION}

Ingestion of foreign bodies into the gastrointestinal tract is not uncommon but mostly accidental. Toddlers and young children are more prone toward oral exploration of their environment, thus enhancing the chances of foreign body ingestion in to $\mathrm{GI}$ tract ${ }^{1,2}$. Incidence of airway intrusion and oesophageal obstruction by foreign body (FB) may increase the risk factor for morbidity and mortality, seeking immediate hospital attention ${ }^{3,4}$. Foreign body while impacted in the GI tract need appropriate medico-surgical intervention or management to remove the object for normal life restoration. In a hospital several such incidences are dealt with much care. The impacted bodies in upper Gl lumen may be catagorised into radio-opaque or radiolucent objects. Commonly ingested radio-opaque FBs include coins, small toys, pencils, pens and caps, chalks, buttons, disc batteries, safety pins, needles, hairpins etc. Whereas the radio lucent objects are mostly bones of fish and meat, food bolus or any soft object. During old days the only management of impacted FB was to push down the object in to the stomach but in recent days the trend are changed to retrieval 5 . Depending upon the infrastructure, equipment and skill of surgeons different strategies are used to remove the FB from upper GIT. However in the present days the success rate for removal of foreign bodies from the upper GIT is 95 to 100 , irrespective of the technique used 6 . The objective of this study is the retrospective review of interventions and management of FB
Key Words: Foreign body, GI tract, Oesophagus, Pharynx, Retrieval, Radio opaque.

\section{${ }^{*}$ Correspondence to:}

\section{Dr. Loknath Sahoo}

PG Student, Department of ENT,

Hi-Tech Medical College \& Hospital,

Bhubaneswar, Odisha, India.

\section{Article History:}

Received: 24-08-2016, Revised: 09-09-2016, Accepted: 14-09-2016

\begin{tabular}{|l|c|}
\hline \multicolumn{2}{|c|}{ Access this article online } \\
\hline Website: & Quick Response code \\
www.jmm.com & \\
\hline DOl: & \\
10.21276/jmrp.2016.2.5.029 & \\
\hline
\end{tabular}

retrieval through sixty different instances for better insight in consolidation.

\section{MATERIAL AND METHODOLOGY}

This retrospective study was done for sixty patients, admitted in the department of ENT of Hi-Tech medical college and Hospital, Bhubaneswar, India during 2014 - 15. Case history was revisited. Patients were of multi age groups and of both the sexes. Detail patient history such as kinds of object, time of ingestion, post ingestion emitting, palpation of the object, odynophagia if any were recorded. All the patients were physically examined. Patients with respiratory distress were supported with oxygen via face mask and linked to pulse oximetry. Some of the patients were administered sedatives intravenously at the recommended dose. Maintaining the airway X-Ray imaging was done to locate the impacted FB in upper GIT. Widening of prevertebral space was suggestive of foreign bodies in the lateral view X-Ray imaging. However the diagnosis was confirmed by X-Ray imaging of neck with posterioanterior and lateral view. The radiolucent objects were visualised by laryngoscope or oesophagoscope. Magill's forceps \& flexible oesophagoscopy with Rat-Tooth forceps were adopted for non-invasive retrieval of FBs from GIT. The patients were kept under observation for few hours and then discharged to look of complication if any. 


\section{RESULTS}

Cases of 60 patients were analysed, who seek the hospital aid to remove the impacted FB. Generally the patients used to rush to hospital with one or more of the following symptoms such as pricking sensation, odynophagia, dysphagia, stridor, fever, vomiting, drooling of saliva after FB ingestion. Some of them were also experienced difficulty in breathing leading to cyanosis. The patients were of all age groups but predominantly (61.67\%) at the age of 2-10 years (Fig 1). Soon after the physical examination and case history the impacted radio opaque FBs were located by $X$ Ray imaging (Fig. 3) or else the object is visualised with the help of laryngoscope/oesophagoscope. In this study the foreign body ingestion incidences were dominated with coins $(n=34)$ followed by fish spine $(n=15)$, meat bones $(n=7)$, safety pin $(n=3)$ and

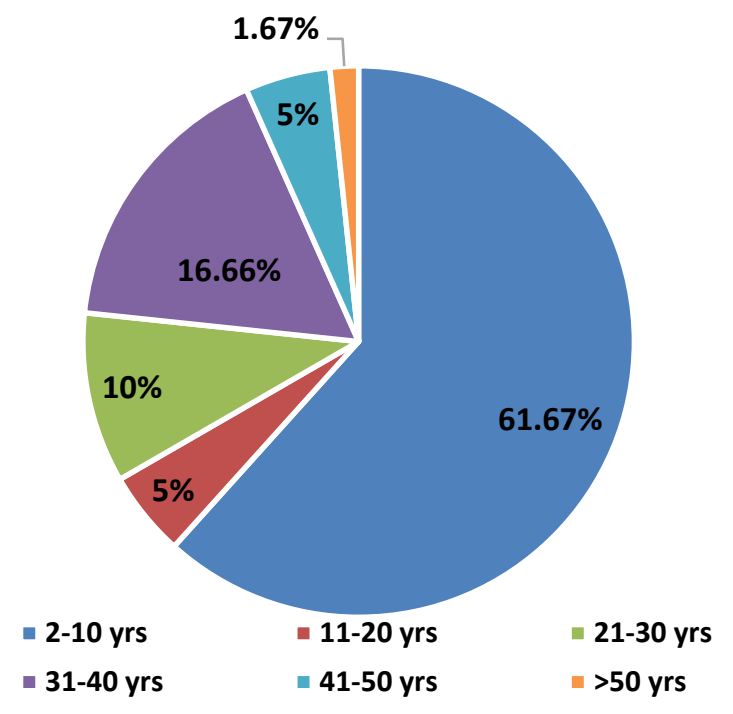

Fig 1: FBs ingestion instances vs. age groups

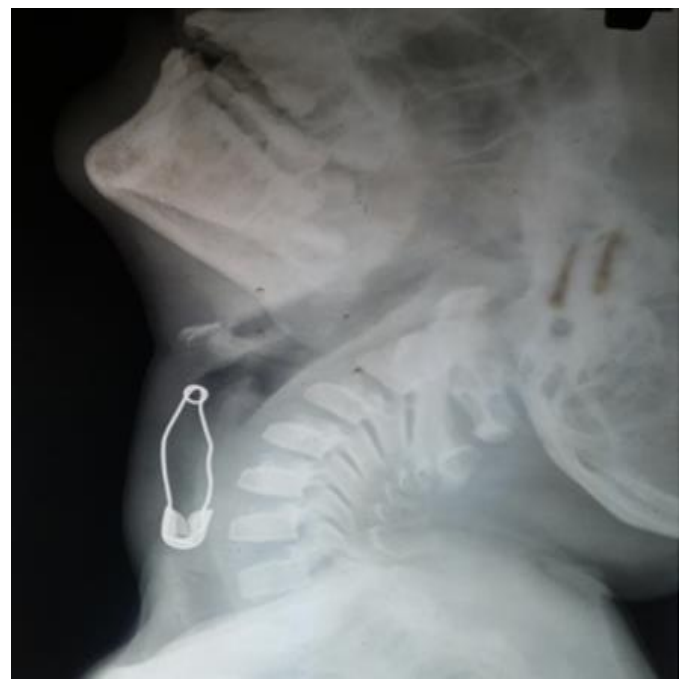

Fig 3: X-Ray image - impacted radio-opaque safety pin

\section{DISCUSSION}

Oral ingestion of foreign bodies is mostly accidental but occurred generally with children, psychiatric patients, prisoners, and edentulous patients ${ }^{7,8}$. It is an established fact that instances of oral ingestion of FB is highest in children ${ }^{1,3,9,10}$. In the present study similar observation is made. The paediatric patients in the age group of 2-10 years were as high as are 37 out of 60 . It is also univocally admitted by many workers that metallic coins are in tablet with cover $(n=1)$. The severity of symptoms depended on the place of impaction in $\mathrm{GI}$ tract. It is found that the impaction of FB at cricopharnyx, at higher score $(75 \%)$ than oropharynx, hypopharynx and oesophagus (Fig. 2). Quick and easy retrieval of the FB gave instant relief to the patient. Many oropharyngeal foreign bodies could be removed without any anaesthesia but 11 such instances needed local anaesthesia for retrieval. In this study in $58 \%$ of cases, FB was removed with Magill's forceps with laryngoscope (Fig. 4) and in 40\% cases with flexible oesophagoscopy. There was no need of any invasive surgical intervention of the upper GIT for retrieval of the FBs nor were any complications detected. In one case the FB was eliminated through the stool.
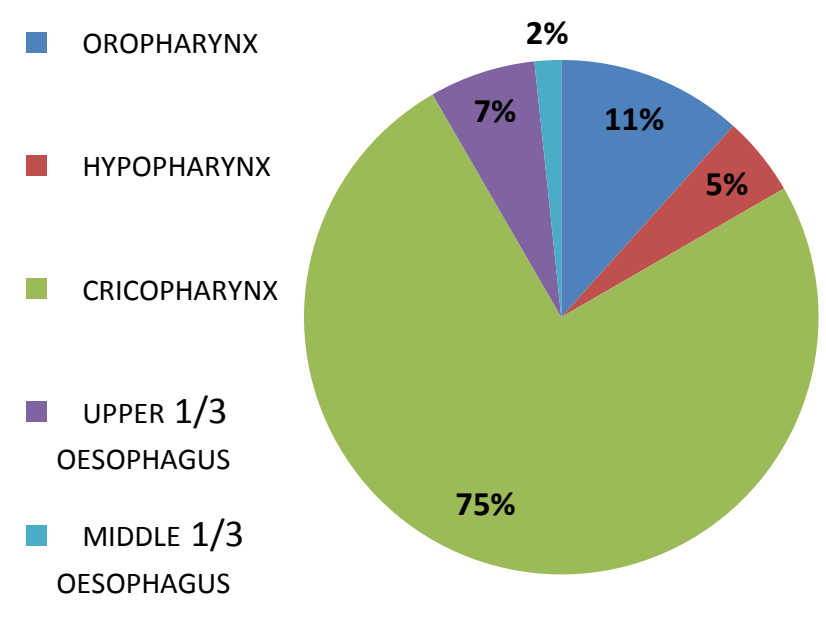

Fig 2: Impaction of FBs in the upper GI tract

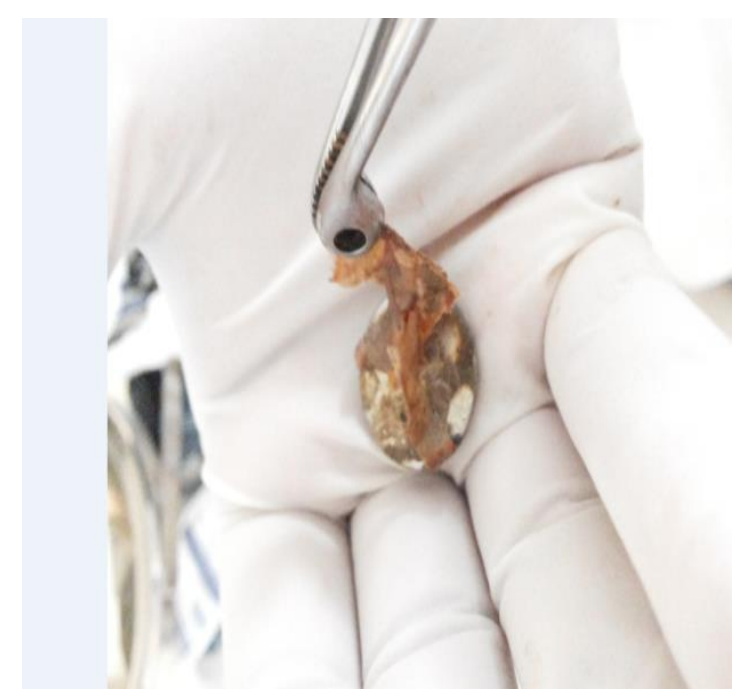

Fig 4: A retrieved coin with Magill's forceps

highest numbers among the ingested $\mathrm{FB}^{8,9,11}$. Impacted coin in lower oesophagus if pushed down to stomach my take its own time to be eliminated through stool asymptomatically. Singh et al., express that the FB if larger than $2 \mathrm{~cm}$ in diameter are difficult to pass the pylorus ${ }^{7}$ therefore pushing management of the object should be done only after assessing the size of the object. Some reviewer opined that the zinc coted coin may have the toxicity effect in human health2 ${ }^{2}$. Coin impaction in upper part of 
oesophagus if not removed could cause oesophageal inflammation, ulceration or perforation ${ }^{2}$. Cricopharynx is the narrowest lumen in the upper GIT in children so possibility of impaction of FB is more in this part. In the present study we could report $75 \%$ of the total incidences as cricopharyngeal impaction. Similar observations are also recorded by many other reviewers ${ }^{1,4,6}$. FB impaction at oropharynx is a serious concern could lead the airways obstruction ${ }^{4,5}$ seven such paediatric patients however could be managed successfully and FBs could be retrieved in the present study. Sharp FB like safety pin, blade pieces, screw bolt bones of fish and meat etc become difficult to manage when found impacted. There was every possibility of rupturing or perforating the GIT at impaction site. Fish and meat bone being the organic in origin and comparatively softer are less harmful than that of safety pin, blade or broken glass pieces. Three incidences of safety pin impaction could be retrieved successfully in the present study without any invasive surgical intervention. Similar observation and management was done to retrieve staple pins by Rehman et al. ${ }^{6}$. Magill's forceps with laryngoscope and flexible oesophagoscopy are two effective and safe interventions for FBs revival5,11,12. In this study out of 60 cases 59 FBs were retrieved by above devices which corroborate the preceding statement. Ingestion of denture is also common in children but the impaction of bigger size denture or denture prosthesis needs early and easy removal ${ }^{13}$. However a single patient with ingestion of denture in the present study could be eliminated the FB through stool safely. Over the year while working we gathered some experiences and skill, which we want to share as tips with the readers.

\section{MANAGEMENT TIPS FOR READER}

- Incidences of foreign body ingestion have been increasing day by day and patients have their absolute expectation for its easy retrieval by a surgeon.

- Listen to the case history from the patient or patient attendant carefully about the shape size of the material ingested and also timing.

- Access the oral cavity and observe the oropharynx by illumination.

- Assess the airway, observe the respiratory pattern, found if it is compromised and extend immediate clinical support.

- Assertion the sign and symptom of the patient by physical examination for any inflammation bleeding and obstruction in upper GIT.

- Decide whether the object is radiolucent or radio opaque.

- Radio opaque FB can be well detected by X-Ray imaging.

- When $\mathrm{x}$-ray imaging finding is negative but the case is highly suspicious for FB, one can go for, endoscopy, ultrasonography, computed tomographic scanning or magnetic resonance imaging to locate the position of $\mathrm{FB}$ and its orientation.

- Be suspicious about the sharp, corrosive and biologically non degradable foreign body like nail, pin, broken glass piece, stone, disc battery, magnet etc. and decide for its quick retrieval or management or treatment if any.

- Create awareness among the patient's relatives, parent to be watchfull in child care to teach other not to be victimized.

Quick and easy retrieval or removal of the FB bring smile on the patient and appreciation to surgeon.

\section{REFERENCES}

1. George Zacur, Joel Friedlander, Antonio J. Quiros, Douglas S. Fishman, and Petar Mamula. Management of Ingested Foreign Bodies in Children: A Clinical Report of the SPGHAN Endoscopy Committee. JPGN 2015; 60: 562-574.

2. Katsinelos, P., G. Paroutoglou, G. Chatzimavroudis, I. Pilpilidis, G. Gelas, C. Zavos, I. Triantafillidis, I. Stergiou, K. Soufleris and T. Vasiliadis. Management of Ingested Foreign Bodies in the Upper Gastrointestinal Tract in Childhood: Experience of 66 cases and suggested recommendations. Annals of Gastroenterology 2007. 20:138-141.

3. Becker B .C and T. G. Nielsen. Foreign bodies in the airways and esophagus in children (Danish)UgeskriftforLaeger 1994;156:433-439.

4. Marisa C. Louie, Stuart Bradin. Foreign Body Ingestion and Aspiration. Pediatrics in Review 2009; 30 136-142.

5. Zeba Ahmed, Salman Mutiullah, Tariq Zahid, Muhammad and Saleem Marfani. Upper gastrointestinal tract foreign bodies: presentation and management. Pakistan J of Surgery2009; 25: 106-9. 6. Rehman Anees Ur, Shahzad Hussain Qadree, Salahu Din and P. Arbi. Esophageal Foreign Bodies - Epidemiology and Management Aspects - A two years retrospective study in tertiary health care center J M H S 2011; .5: 623-627.

7. Singh Gurjit, Surendra Sharma, Shrikant Khurade, and Somnath Gooptu. Ingested Foreign Bodies in Children: A Report of Two Cases. J. Family Med. Prim Care 2014; 3: 452-455.

8. Singh H., B, Dhingra, D. Yadav and V. Aggarwal. Esophageal Foreign Body in a Neonate: An unusual age of presentation. J. Nepal Paediatr. Soc 2012; 32 : 79-80

9. Nahoman, B.Y and C.F Mueller. Asymptomatic esophageal perforation by a coin in a child. Am Emerg.Med. 2000; 13:93.

10. Robert E. Kramer, Diana G. Lerner, Tom Lin, Michael Manfredi, Manoj Shah, Saki N, Nikakhlagh S, Safai F, Peyvasteh and M. Esophageal Foreign bodies in children: Pak. J. Med Sci 2007; 23: 854-856.

11. Thomas C. Stephen, Troy E. Gibbons, Harpreet Pall, Ben Sahn, Mark McOmber and Webb W.A. Management of foreign bodies of the uppergastrointestinaltract:Update.GastrointestEndosc1995.;41:39-51. 12. Baral B. K, R. R. Joshi, B.K. Bhattarai and R.B Sewal. Removal of coin from upper esophageal tract in children with Magill's forceps under propofol sedation. Nepal Med. Coll. J. 2010; 12 : 38-41.

13. Abdullah B.J, L.K, Teong, J. Mahadevan and A. Jalaludin. Dental prosthesis ingested and impacted in the esophagus and orolaryngopharynx. J. Otolaryngol. 1998; 27: 190-194.

14. Mondal PJ, Somnath Saha, Anirban Ghosh and Mousumi Sengupta. Removal of Foreign Bodies from Esophagus with Flexible Endoscope - A Case Report. Indian J Otolaryngology Head Neck Surg 2014. 66: 78-80.

\section{Source of Support: Nil. Conflict of Interest: None Declared.}

Copyright: () the author(s) and publisher. IJMRP is an official publication of Ibn Sina Academy of Medieval Medicine \& Sciences, registered in 2001 under Indian Trusts Act, 1882.

This is an open access article distributed under the terms of the Creative Commons Attribution Non-commercial License, which permits unrestricted non-commercial use, distribution, and reproduction in any medium, provided the original work is properly cited.

Cite this article as: Loknath Sahoo, Rajesh Kumar Padhy, Devanand Mohapatra, Sudeepta Ashe. Foreign Bodies in Upper Gastrointestinal Tract: A Retrospective Analysis of Clinical Intervention and Management. Int J Med Res Prof. 2016; 2(5):146-48. 